\title{
Fixation of Distal End Femoral Fracture in a Dog with Arrow Pinning: A Case Report
}

\author{
Manav Sharma, D.K. Sarma* and P.K. Boro \\ Lakhimpur College of Veterinary Science, Assam Agricultural University, \\ North Lakhimpur, Assam, India \\ *Corresponding author
}

\section{A B S T R A C T}

\section{Keywords}

Arrow pin, Supracondylar, Metaphyseal,

Femur fracture, Internal fixation

Article Info

Accepted:

20 February 2018

Available Online:

10 March 2018
A nine months old local female dog, presented to Teaching Veterinary Clinical Complex, Lakhimpur College of Veterinary science, Assam Agricultural University with the history of automobile accident. Radiographic evaluation revealed distal end metaphyseal or supracondylar femoral fracture on left leg. An intramedullary pin was fabricated to arrow shaped pin and was inserted completely in retrograde manner for internal surgical immobilization of the fractured part. Robert Jones Bandage was also applied for two months to restrict stifle movement. Radiographic evaluation after 3 months revealed mature callus formation without pin displacement. On the basis of the findings an inference could be drawn that single arrow pin internal fixation is sufficient for supracondylar or distal end metaphyseal femoral fracture in dog.

\section{Introduction}

Dogs are most adored animal species and considered as oldest companion animal of human being. In advanced society they are now getting utmost care, management and treatment. However, the exponential growth of automobiles on road has also equally increased the statistical numbers of accidental injuries and death of both the pet and stray animals. Out of various automobile accidental cases the veterinary surgeons encountered, the more frequent is the femur fracture. This may be due to " $\mathrm{S}$ " shaped (anatomical curvature of shaft) structure of the bone. Among various form of femur fractures the distal end femoral fracture or supracondylar (Slatter, 1993) or metaphyseal fracture is commonly noticed in dogs (Alcantara and Stead, 1975) due to caudal bowing of distal femoral end. The present communication reports a case successful repairing of distal end femoral fracture in a local dog with arrow pinning.

\section{Case history and treatment}

A one year old indigenous female dog was brought to the Teaching Veterinary Clinical Complex, Lakhimpur College of Veterinary Science, Assam Agricultural University, and North lakhimpur with the history of 
automobile accident. Clinical investigation revealed a few lacerated wound on the hind part of body with loss of weight bearing capacity by the left hind leg. Distal end femoral (metaphyseal or supracondylar) fracture was confirmed by physical and radiographic investigations (Fig. 1). A chip fracture of tibial tuberocity was also observed.

\section{Arrow pin preparation}

Based on the radiograph and size of the dog an intramedullary pin $(2.4 \mathrm{~mm})$ was selected. Then the intramedullary pin was cut to a required length and fabricated manually by heating and hammering the cut end to make flat and subsequently made smooth by rubbing against rough surface. Finally the flat end was given arrow shape by cutting with hacksaw blade (Fig. 2). It was then cleaned and sterilized before application.

Anaesthetic management was carried out by $16 \mathrm{hrs}$ fasting. Premedication was done with intravenous administrations of Atropine (Tropine; Neo Labs) @ 0.04 mg/kg body weight and Diazepam (Lori; NEON) @ 0.5 $\mathrm{mg} / \mathrm{kg}$ body weight at 10 minutes interval. Intermittent bolus dosing of Ketamine@ $10 \mu$ $\mathrm{g} / \mathrm{kg} / \mathrm{min}$ was infused (Aneket; Neo Labs) via Normal Saline using intravenous canola for maintenance. Suxamethonium chloride (Scoline; GSK) @ $0.3 \mathrm{mg} / \mathrm{kg}$ bwt was also administered for proper muscle relaxation. Omeprazole (Omez; Dr Reddy’s) @ 0.5mg/kg bwt IVly was also administered 30 minutes before premedication. Craniolateral surgical approach to fractured site showed caudal displacement of distal fractured end and a large hematoma. Fractured fragments were reduced and aligned with the help of osteotome and bone-holding forceps. Retrograde introduction of the arrow pin was done in between the trochlear ridge with the help of manual bone driller. The pin was completely inserted into the distal fractured end with the help of mallet. Surgical wound was closed by standard surgical procedure using 1-0 chromic catgut for joint capsule, fascialata, subcutaneous tissue and 2-0 black braided silk for skin. Robert Jones Bandage was applied for restriction of the joint movement for one month with re-bandaging at 15 days interval. Post operative medical care was achieved by administration of Ceftriaxone (Intacef; Intas Pharmaceuticals Ltd.) @ $25 \mathrm{mg} / \mathrm{kg}$ bwt $/$ day IM for 7 days, Tramadol (Contramal; Piramal HC) @ 1.2 $\mathrm{mg} / \mathrm{kg}$ bwt/day IM for 5 days and chlorpheniramine maleate (Zeet; Alembic) @ $0.5 \mathrm{mg} / \mathrm{kg}$ bwt/day IM for 5 days. Omeprazole (Omez; Dr Reddy's) @ 0.5mg/kg bwt/day orally was continued for four days post operatively. Owner was advised to restrict the activity of the animal for at least two months. Skin sutures were removed on $10^{\text {th }}$ day. The dog was regularly monitored at 15 days interval for four months for the evidence of any arthritis, joint pain or gait abnormalities. Radiographic monitoring after three months showed matured callus formation surrounding fractured site without pin migration (Fig. 3) indicating complete healing of fracture. Healing of fractured tibial tuberocity was also found to be satisfactory. Complete functional recovery without any clinical abnormalities and complications was noticed up to 6 months after treatment (Fig. 4). Lacerated wounds over the body were also treated locally with antiseptics and recovered accordingly.

\section{Discussion}

Frequent occurrence of distal end femoral fracture may be due to caudal bowing of distal epiphysis with respect to the diaphyseal bony column. The challenges before veterinarians in correcting these fractures are due to insufficient bone for orthopedic implants, presence of soft cancellous bone as well as the area is predisposed to considerable 
bending forces (Harasen, 2002). Different methods of internal fixation such as multiple divergent Steinmann pins or Kirschner wires application, use of Rush pinning technique, cross pinning, Lag screw application and even bone plates are in practice (Slatter, 1993). These techniques has various drawbacks like improper reduction or pin placement, muscle tie-down, soft tissues irritation and joint pain or arthritis due to injuries by cut ends of pins and pin migration. These may results in complication like lameness or loss of normal motion of the stifle joint (Dehghani et. al., 2013) and functional recovery is not satisfactory (Alcantara and Stead, 1975). Moreover, these techniques need multiple internal implants and some of them require second surgical intervention for removal of implants.

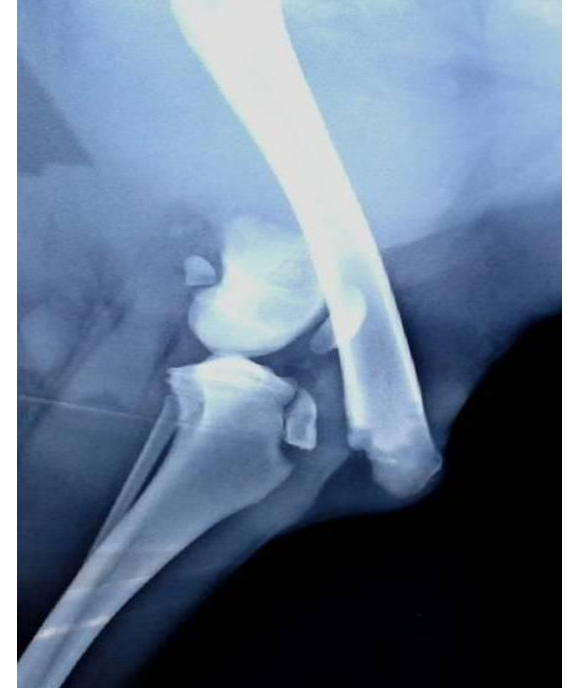

Fig.1 Radiograph showing fractured- tibial tuberocity and distal femur

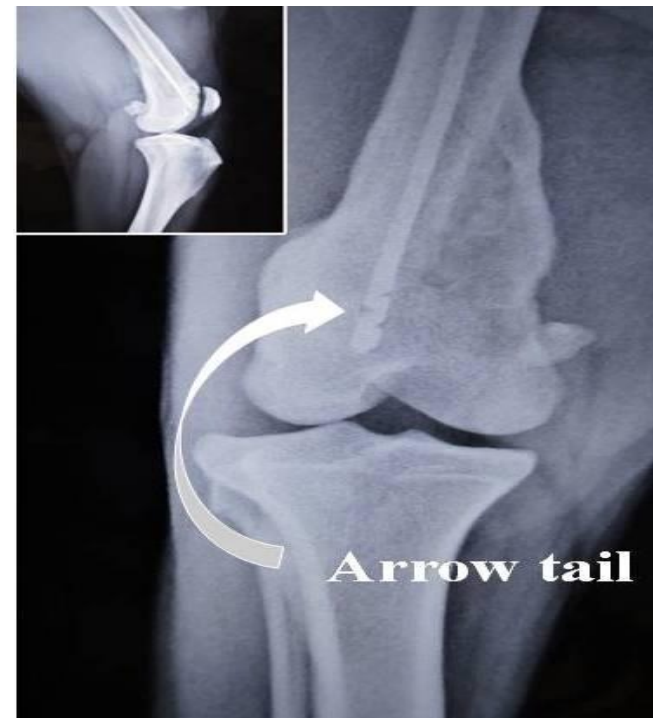

Fig.3 Radiograph after 3 months ofoperation with mature callus (inset lateralview showing healed tibial tuberocity).

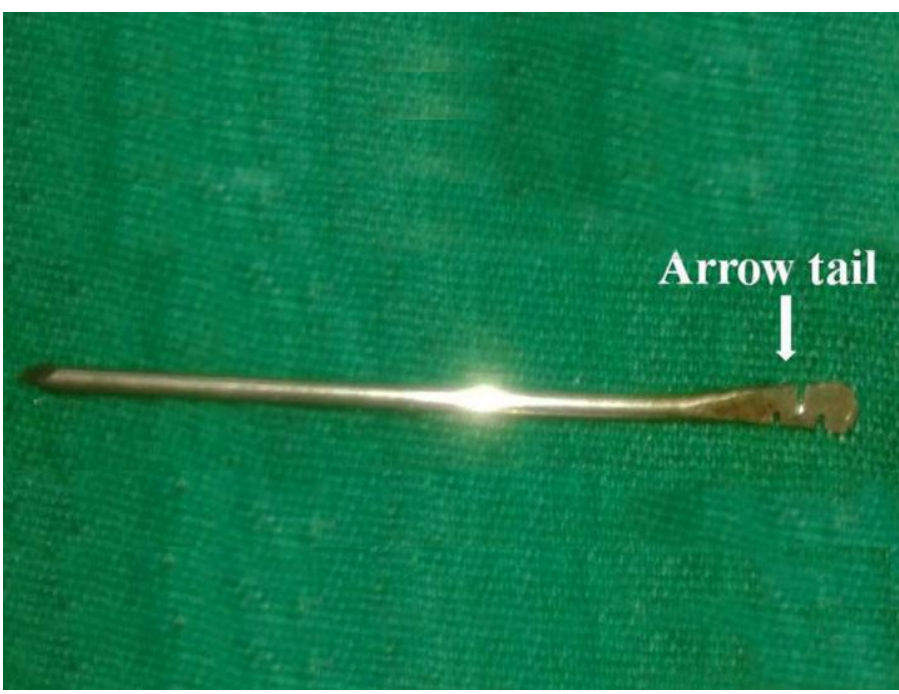

Fig.2 Fabricated stainless steel arrow pin

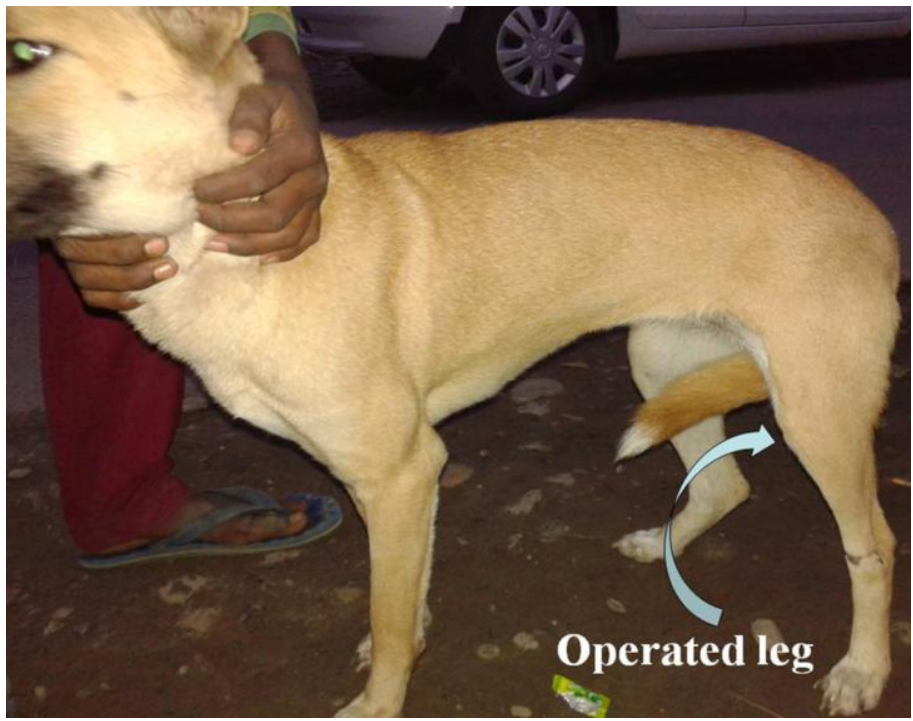

Fig.4 Dog after 6 months of operation 
In the present case, retrograde insertion of arrow pin along with external fixation (Robert Jones Bandage) was found to be helpful in distal end femoral fracture. The arrow tail of the pin prevented the movement of the pin and held both the ends in place. Though at the time of insertion of arrow tail may cause tissue damage but subsequent growth of bony tissue and anchoring by arrow tail might have effectively prevented both the backward and forward pin migration. This was best represented by absence of complications and good functional recovery up to the 7 months post operation in the present case. Immobilization resulting from restricted movement and application of Robert Jones Bandage in the initial phase of fracture healing might have induced healing of fractured tibia (Slatter, 1993).

From the findings of the present study it could be concluded that single arrow pin of right dimension and length is sufficient to correct distal end femoral fracture or metaphyseal or supracondylar fracture in adult dogs. The result could not be compared due to paucity of literatures and perhaps, this seems to be the first report of arrow pinning in dog from India.

\section{Acknowledgement}

The authors are thankful to Dr. Raju Dutta, Veterinary Officer, of Dhemaji district for his kind cooperation during the course of treatment of the dog.

\section{References}

Alcantara, PJ and Stead, AC (1975). Fractures of the distal femur in the dog and cat. J. Small Anim. Practice. 16: 649-659.

Dehghani, NS; Raayat, JAR; Foroud, M; Vesal, N and Hooman, F (2013). Surgical repair of distal femoral fracture in a wild gray wolf (Canis lupus). Iranian J. Vet. Res., 14: 165168.

Harasen, G (2002). Fractures involving the distal extremity of the femur: Part 2the mature patient. J. Small Anim. Practice., 43: 131-132.

Slatter, D (1993). Fracture of the Femur. In: Simpson, D.J. and Lewis, DD (Eds.), Text Book of Small Animal Surgery ( $3^{\text {rd }}$ Edn.), D. D. Saunders, Philadelphia, (a, b). PP: 2059-2089.

\section{How to cite this article:}

Manav Sharma, D.K. Sarma and Boro, P.K. 2018. Fixation of Distal End Femoral Fracture in a Dog with Arrow Pinning: A Case Report. Int.J.Curr.Microbiol.App.Sci. 7(03): 2161-2164. doi: https://doi.org/10.20546/ijcmas.2018.703.254 